\title{
Effect of strain and inoculation dose of classical swine fever virus on within-pen transmission
}

\author{
Eefke Weesendorp ${ }^{1,2 *}$, Jantien Backer ${ }^{1}$, Arjan Stegeman $^{2}$, Willie Loeffen ${ }^{1}$ \\ ${ }^{1}$ Department of Virology, Central Veterinary Institute of Wageningen UR, P.O. Box 65, $8200 \mathrm{AB}$, \\ Lelystad, The Netherlands \\ ${ }^{2}$ Department of Farm Animal Health, Faculty of Veterinary Medicine, University of Utrecht, \\ Yalelaan 7, 3584 CL, Utrecht, The Netherlands
}

(Received 23 December 2008; accepted 23 July 2009)

\begin{abstract}
To improve the understanding of the dynamics and options for control of classical swine fever (CSF), more quantitative knowledge is needed on virus transmission. In this study, virus excretion and within-pen transmission of a strain of low, moderate and high virulence were quantified. Furthermore, the effect of inoculation dose on excretion and transmission were studied. The transmission was quantified using a stochastic susceptible-exposed-infectious-recovered (SEIR) model. Five transmission trials were conducted with ten pigs each. In each trial, three pigs were inoculated with the low virulent strain Zoelen, a low $\left(10^{2} \mathrm{TCID}_{50}\right)$, middle $\left(10^{3.5} \mathrm{TCID}_{50}\right)$, or high dose $\left(10^{5} \mathrm{TCID}_{50}\right)$ of the moderately virulent strain Paderborn, or the highly virulent strain Brescia. The other seven pigs in each trial served as contact pigs. None of the pigs inoculated with the low dose of the Paderborn strain were infected. When it was assumed that the infectiousness of the pigs coincided with virus isolation positive oropharyngeal fluid and/or faeces, no significant differences in transmission rate $\beta$ and basic reproduction ratio $R_{0}$ between the high inoculation dose of the Paderborn strain $\left(\beta=1.62 /\right.$ day, $\left.R_{0}=35.9\right)$ and the Brescia strain $(\beta=2.07 /$ day, $\mathrm{R}_{0}=17.5$ ) were observed. When the middle dose of the Paderborn strain was used for inoculation, the $\beta$ (5.38/day) was not significantly higher than the Brescia strain or the high inoculation dose of the Paderborn strain, but the $\mathrm{R}_{0}(148)$ was significantly higher. Infection with the Zoelen strain resulted in a significantly lower $\beta$ and $R_{0}\left(\beta=0 /\right.$ day, $\left.R_{0}=0\right)$ than the other strains.
\end{abstract}

classical swine fever / transmission parameter / virus excretion / within-pen transmission

\section{INTRODUCTION}

Classical swine fever (CSF) is a highly contagious viral disease that affects domestic pigs and wild boar. For many European countries with a non-vaccination policy this is an exotic disease, but outbreaks occur occasionally. In areas with a high pig density, this has resulted in severe economic losses due to mass destruction of pigs and export limitations [16].

\footnotetext{
* Corresponding author: eefke.weesendorp@wur.nl
}

Classical swine fever virus (CSFV) is excreted by infected pigs in saliva, nasal and lacrimal fluids, faeces and urine [19, 28]. Infected pigs can transmit the virus to susceptible pigs via these secretions and excretions. This can occur by direct contact, or indirectly via contaminated clothes, livestock trucks, buildings or fomites [20, 21]. The efficiency and speed of transmission are dependent on several underlying parameters. For one, this includes the amounts of infectious virus excreted by infected pigs in their secretions and excretions, which may in turn depend on 
age and breed of the pigs, virus strain, inoculation dose or immune status. Additional important parameters include contact structure between infectious and susceptible pigs, survival of virus in the environment and the susceptibility of contact pigs.

Direct transmission can be studied in transmission experiments where a number of pigs is inoculated with the virus and subsequently virus transmission to contact pigs within the same pen is studied [4]. The transmission rate $\beta$ and the basic reproduction ratio $\left(\mathrm{R}_{0}\right)$ can then be used to quantify the transmission. The transmission rate $\beta$ is defined as the number of secondary infections caused by one infectious individual per unit of time. The $\mathrm{R}_{0}$ is defined as the average number of secondary infections caused by one infectious individual during its entire infectious period in a fully susceptible population. If $\mathrm{R}_{0}$ is smaller than 1 , the infection within the population will fade out. If the $R_{0}$ is greater than 1 , a large outbreak can occur. The $\beta$ and $R_{0}$ can be estimated using a susceptibleexposed-infected-recovered (SEIR) model [7, 11]. This model describes the transmission dynamics by the change in the number of susceptible pigs $(S)$, the number of pigs that are infected but not yet infectious $(E)$, the number of infectious pigs $(I)$, and the number of pigs that recovered or died $(R)$ per unit of time. This requires assumptions regarding the start and duration of the infectious period of infected animals and the moment of infection of contact pigs. In previous studies, mostly viraemia was used to determine this ${ }^{1}$ [8, 13-15]. The main problem with viraemia is that the virus is isolated from a site from which it cannot be transmitted to other pigs, and viraemia does not necessarily coincide with virus excretion in secretions and excretions [28]. Furthermore, for the determination of the moment of infection of contact pigs, viraemia does not seem to be the most biologically appropriate measure,

\footnotetext{
${ }^{1}$ Klinkenberg D., Bouma A., Floegel-Niesmann G., De Jong M.C.M., E2 subunit marker vaccines reduce transmission of classical swine fever virus sufficiently to halt epidemics, Ph.D. thesis, University of Utrecht, The Netherlands, 2003, pp. 37-60.
}

since the virus replicates first in the tonsil and pharyngeal region, after which it can infect other animals via oronasal secretions. Viraemia occurs in a later stage of the infection. As a result, the transmission parameters could be over- or underestimated.

Previous studies have estimated transmission parameters, but only limited data was available on underlying parameters like virus excretion, and their relation to transmission ${ }^{1}[8,13]$. For three strains, of either high, moderate or low virulence, we have detailed information on excretion dynamics [28]. However, information on the transmission characteristics of these strains is limited or lacks accuracy, as described above. Knowledge on transmission mechanisms is needed to know how transmission can be reduced during an outbreak. Especially information on underlying parameters of transmission like virus excretion and their relation to transmission are needed.

Therefore, we studied the virus excretion and the within-pen transmission of the same highly, moderately and low virulent strains, as we used in the previous study on excretion dynamics. Moreover, the effect of the inoculation dose on excretion and transmission was studied, since pigs are infected during outbreaks with varying doses of virus. We used different assumptions on infectiousness of pigs to study the relationship between virus excretion and transmission.

\section{MATERIALS AND METHODS}

\subsection{Experimental design}

Five transmission experiments were carried out with ten pigs each. Each transmission experiment was performed in a separate room of an isolation unit. At the start of the experiment, three pigs were removed from each group and intranasally inoculated. After $24 \mathrm{~h}[3,12,23]$, the inoculated pigs were returned to their original groups, allowing contact exposure of the remaining seven pigs. Each group was inoculated with a different virus strain or dose. The experiment was terminated 35 days post-inoculation (p.i.). This experiment was approved by the Ethics Committee for Animal Experiments of the Animal Sciences Group of Wageningen UR. 


\subsection{Experimental animals}

Eight-week-old male pigs were obtained from a conventional, but pestivirus free pig herd in the Netherlands, and were randomly divided into the five groups. The pigs were fed once a day and had unlimited access to water.

\subsection{Viruses and inoculation of animals}

In the first experiment, three pigs were inoculated with a dose of $10^{5} \mathrm{TCID}_{50}(50 \%$ tissue culture infectious dose) of the low virulent strain Zoelen (genotype 2.2), used at cell passage level 3. This strain was originally isolated during an outbreak on a Dutch farm. In the second, third and fourth experiment, three pigs each were inoculated with the moderately virulent strain Paderborn, with doses of respectively $10^{2}$ TCID $_{50}$ (Paderborn low dose), $10^{3.5}$ TCID $_{50}$ (Paderborn middle dose), and $10^{5} \mathrm{TCID}_{50}$ (Paderborn high dose). This strain (genotype 2.1) was isolated in 1997 during the outbreak in the Paderborn area of Germany [10], and was used at cell passage level 5 . In the fifth experiment, three pigs were inoculated with a dose of $100 \mathrm{LD}_{50}(50 \%$ lethal dose $)$, which is approximately $10^{2.5} \mathrm{TCID}_{50}$, of the highly virulent strain Brescia. The virus stock was heparinised blood from a pig infected with Brescia strain 456610 (genotype 1.2). This strain was derived from a strain obtained in 1951 from Brescia, Italy. The strains were classified as low, moderately or highly virulent based on the classification of CSFV strains by Van Oirschot [25]. One milliliter of the virus suspension was administered per animal $(0.5 \mathrm{~mL}$ per nostril). The inocula were back titrated to confirm the dose administered.

\subsection{Clinical signs and body temperature}

Clinical signs and rectal body temperatures were recorded daily. Fever was defined as a body temperature higher than $40{ }^{\circ} \mathrm{C}$, for two or more consecutive days. For quantitative assessment of the severity of disease a list of ten CSF-relevant criteria, as described by Mittelholzer et al. [17] was used. For each criterion a score was recorded of either normal (score 0), slightly altered (score 1), distinct clinical symptom (score 2), or severe CSF symptom (score 3). The scores for each pig were added up to a total score per day, with a maximum of 30 . Only pigs with total clinical scores (CS) higher than 2 were defined as pigs having clinical symptoms due to the CSFV infection. Sick pigs that became moribund and unable to stand up were euthanized for reasons of animal welfare.

\subsection{Sampling procedures}

Serum and EDTA-blood samples were collected from each pig at days $0,3,5,7,10,12,14,17,19$, $21,24,28$, and 35 p.i. Serum samples were stored at $-70{ }^{\circ} \mathrm{C}$ until testing for antibodies in the ELISA and NPLA (neutralization peroxidase-linked assay). EDTA-blood samples were used for immediate leukocyte counts and isolation of leukocytes. For isolation of the leukocytes, $4 \mathrm{~mL} 0.84 \% \mathrm{NH}_{4} \mathrm{Cl}$ solution was added to $2 \mathrm{~mL}$ of EDTA blood. After $10 \mathrm{~min}$ the samples were centrifuged at $300 \mathrm{~g}$ and washed twice with phosphate-buffered saline (PBS). The pellet was resuspended in $2 \mathrm{~mL}$ medium (Eagle minimum essential medium (EMEM) with $5 \%$ foetal bovine serum (FBS), and 10\% antibiotics solution ABII $(1000 \mathrm{U} / \mathrm{mL}$ Penicillin, $1 \mathrm{mg} / \mathrm{mL}$ Streptomycin, $20 \mu \mathrm{g} / \mathrm{mL}$ Fungizone, $500 \mu \mathrm{g} / \mathrm{mL}$; Polymixin $\mathrm{B}$, and $10 \mathrm{mg} / \mathrm{mL}$ Kanamycin)) and stored at $-70{ }^{\circ} \mathrm{C}$ until analysis in the virus isolation (VI).

Oropharyngeal fluid and faeces were collected at days $0,3,4,5,6,7,8,10,11,12,13,14,15,17$, $19,21,24,26,28,31,33$, and 35 p.i. Oropharyngeal fluid was obtained with a gauze tampon held by a $30 \mathrm{~cm}$ long forceps, which was scrubbed against the dorsal wall of the pharynx behind the soft palatum. The tampons were not weighed, so the total amount of oropharyngeal fluid in each tampon was not exactly known, however, based on a previous experiment the average weight is approximately $1.0 \mathrm{~g}$ (with a standard deviation of $0.4 \mathrm{~g}$ ) [28]. The oropharyngeal fluid was suspended in 4 $\mathrm{mL}$ of the same media as described for the leukocyte isolation. After centrifugation $(1800 \mathrm{~g}$ for $15 \mathrm{~min}$ ) the samples were stored at $-70{ }^{\circ} \mathrm{C}$ until analysis in the VI and Real-Time Reverse Transcription Polymerase Chain Reaction (RRT-PCR). Faeces were collected from the rectum by stimulation of the anus. One gram of faeces was suspended in $9 \mathrm{~mL}$ medium (EMEM containing 10\% FBS and 10\% antibiotics solution ABII) and vortexed with glass beads. After centrifugation (2 $500 \mathrm{~g}$ for $15 \mathrm{~min}$ ) the supernatants were stored at $-70{ }^{\circ} \mathrm{C}$ until analysis in the VI and RRT-PCR.

Tonsils were collected from all pigs during the post-mortem examination at day 35 p.i., or at an earlier time-point when pigs died or were euthanized for reasons of animal welfare. From each tonsil $0.1 \mathrm{~g}$ was added to $0.5 \mathrm{~mL}$ of medium (same as for isolation of leukocytes), and homogenized in the MagNa Lyser (Roche Applied Science, Mannheim, Germany) for $30 \mathrm{~s}$ at $3500 \mathrm{~g}$. After centrifugation (9 $500 \mathrm{~g}$ for $1 \mathrm{~min}$ ), an additional $1 \mathrm{~mL}$ of medium was added. Samples were centrifuged again 
(9 $500 \mathrm{~g}$ for $5 \mathrm{~min}$ ) and the supernatant was stored at $-70{ }^{\circ} \mathrm{C}$ until analysis in the RRT-PCR.

\subsection{Tests}

\subsubsection{Leukocyte counts}

Leukocyte counts were performed using the Medonic $^{\circledR}$ CA 620 coulter counter (Boule Medical AB, Stockholm, Sweden). A decrease in the number of leukocytes (leukopenia) is a typical sign of CSF [25]. Leukopenia was defined as $<10 \times 10^{9}$ cells $/ \mathrm{L}$ blood [28].

\subsubsection{Virus isolation and titration}

Presence of infectious virus in the samples was tested by virus isolation. From oropharyngeal fluid and faeces, a volume of $250 \mu \mathrm{L}$ was incubated for $1 \mathrm{~h}$ on a monolayer of SK6 cells (permanent porcine kidney cell line) in a 24-well plate (Corning Incorporated, Corning, USA) at $37{ }^{\circ} \mathrm{C}$ in an atmosphere with $5 \% \mathrm{CO}_{2}$. Plates were then washed once with PBS and fresh medium was added to the wells. From leukocyte samples, a volume of $125 \mu \mathrm{L}$ was directly incubated on a monolayer of SK6 cells without washing. Cells were cultured at $37{ }^{\circ} \mathrm{C}$ in an atmosphere with $5 \% \mathrm{CO}_{2}$. After four days, the growth medium was discarded, and the monolayers were washed in a $0.15 \mathrm{M} \mathrm{NaCl}$ solution, dried for $1 \mathrm{~h}$ at $37{ }^{\circ} \mathrm{C}$ and frozen for $1 \mathrm{~h}$ at $-20^{\circ} \mathrm{C}$. The monolayers were fixed with $4 \%$ cold $\left(5{ }^{\circ} \mathrm{C}\right)$ paraformaldehyde in PBS for $10 \mathrm{~min}$ and then washed in $0.15 \mathrm{M} \mathrm{NaCl}$. Monolayers were stained by the immunoperoxidase monolayer assay (IPMA) [29], using two horse-radish peroxidase (HRPO)-conjugated CSFV specific MAbs (V3/V4) diluted in PBS (1:4 000) with 4\% horse serum. Monolayers were stained with $300 \mu \mathrm{L}$ $0.05 \mathrm{M} \mathrm{NaAc}$ solution, containing 5\% 3-amino-9ethyl carbazole (AEC) and $0.05 \% \mathrm{H}_{2} \mathrm{O}_{2}$, and examined for stained cells. Virus positive samples were titrated in four-fold after making five decimal dilutions. Virus titres were calculated as $\mathrm{TCID}_{50}$ using the Spearman-Kärber method [9].

\subsubsection{RRT-PCR}

The presence of viral RNA in oropharyngeal fluid, faeces and tonsils was analyzed by RRTPCR. For RNA isolation, $200 \mu \mathrm{L}$ of the samples were pipetted manually into MagNA Pure sample cartridges (Roche Applied Science). The RNA was extracted with the Total Nucleic Acid Isolation Kit
(Roche Applied Science) according to the manufacturer's instructions using the automated MagNA Pure LC instrument (Roche Applied Science). After the MagNA Pure completed the RNA isolation, the nucleic acids were removed from the MagNA Pure LC and immediately processed for the RRT-PCR or stored at $-70{ }^{\circ} \mathrm{C}$ in the sample cartridge until the RRT-PCR was carried out.

The RRT-PCR was performed with a LightCycler (LC) instrument (Roche Applied Science) using the RNA Master Hybridization Probes Kit, as described by Van Rijn et al. [26]. Analysis was performed with the LC software.

\subsubsection{Serology (ELISA and NPLA)}

The serum samples were tested for antibodies by the PrioCHECK ${ }^{\circledR}$ CSFV Ab (Prionics AG, Lelystad, The Netherlands), an ELISA for detecting CSFV-specific (E2) antibodies [1]. The results are expressed as the percentage inhibition. A cut-off value of $30 \%$ inhibition was applied. Samples with the percentage of inhibition above $30 \%$ were considered positive.

Serum samples were tested in the direct NPLA for neutralizing antibodies against the homologous CSFV strains [22]. Serial two-fold dilutions (1:5 to $1: 10240)$ of serum were mixed with an equal volume $(50 \mu \mathrm{L})$ of CSFV (containing $\left.100 \mathrm{TCID}_{50}\right)$ in a 96-well plate (Greiner, Frickenhausen, Germany). After incubation of $1 \mathrm{~h}$ at $37{ }^{\circ} \mathrm{C}$ in an atmosphere with $5 \% \mathrm{CO}_{2}, 100 \mu \mathrm{L}$ SK6 cells (approximately 10000 cells) in medium (Medium Earle's Balanced Salts with $0.55 \%$ lactalbumin hydrolysate, $1 \%$ MEM vitamin solution (Gibco, Paisley, UK), 5\% FBS, $1 \%$ Penstrep $(10000 \mathrm{U} / \mathrm{mL}$ Penicillin, $10000 \mu \mathrm{g} / \mathrm{mL} \quad$ Streptomycin), $1 \%$ Fungizone $(250 \mu \mathrm{g} / \mathrm{mL}), 1 \%$ L-Glutamin $(200 \mathrm{mM}))$ were added per well. After four days, an IPMA was used for staining virus positive monolayers. The antibody titre was then determined as the reciprocal of the highest two-fold serum dilution that neutralized all virus.

\subsection{Statistical analysis and quantification of transmission parameters}

\subsubsection{Virus excretion}

Differences in virus excretion between the strains and doses were compared during the first days of virus excretion until the moment contact pigs were infected. This was in general within 5 days after the start of virus excretion. Differences in virus 
excretion of the inoculated pigs between strains and doses were determined by calculating for each individual inoculated pig the total amounts of virus excreted in faeces and oropharyngeal fluid (in $\mathrm{TCID}_{50}$ ), which was expressed by the cumulative excretion (against time). Differences between the strains and doses in mean cumulative virus excretion (in $\log _{10} \mathrm{TCID}_{50}$ ) were statistically analysed using an analysis of variance (ANOVA) model. Pair wise comparisons between strains were made using the Bonferroni method (with an experiment wise Type I error rate of 0.05). Calculations were performed with SPSS 12 (SPSS Inc., Chicago, USA).

\subsubsection{Estimation of transmission parameters}

For the analysis of the transmission, a stochastic SEIR model was used [7, 11]. In a SEIR model, the transmission dynamics of infectious diseases between individuals are described by the change in the number of susceptible $(S)$, exposed $(E)$, infectious $(I)$, recovered or removed (dead) $(R)$ and total number $(N)$ of animals. Assuming that the number of contacts per animal is independent of the herd size (frequency dependent mixing) [2], susceptible pigs become infected with a rate $\mathrm{d} S_{t} / \mathrm{d} t=-\beta \cdot S_{t} \cdot I_{t} / N_{t}$. In this formula, $\beta$ is the transmission rate and can be interpreted as the average number of new infections for a typical infectious animal in a susceptible population per unit of time. $S_{t}$ is the number of susceptible animals, $I_{t}$ is the number of infectious animals and $N_{t}$ is the total number of animals at time $t$. The probability for a susceptible animal to become (latently) infected during period $\Delta t$ is $P(S \Rightarrow E)=1-\exp \left(-\beta \cdot I_{t} \Delta t / N_{t}\right)$, and the probability for a susceptible animal to escape infection during a period $\Delta t$ is given by $P(S \nRightarrow E)=\exp \left(-\beta \cdot I_{t} \cdot \Delta t / N_{t}\right)$. The distribution of the infectious period is modeled by a beta distribution with a maximum of 60 days, of which the mean infectious period $T i$ and the standard deviation are estimated from the data. Pigs infected with the strains used in this study died or recovered in previous studies before day 60 p.i. ${ }^{1}$ [28]. The reproduction number $\mathrm{R}_{0}$ is the expected number of new infections an average infectious animal causes during its entire infectious period in a fully susceptible population, i.e. $\beta^{*} T i$. All transmission parameters are estimated by maximizing their corresponding loglikelihood functions. The $95 \%$ confidence intervals are obtained from the loglikelihood profile, assuming that the loglikelihood ratio is described by a chi-square distribution with one degree of freedom.

To estimate $\beta$ and $R_{0}$ from the transmission experiments, the moment contact pigs became infected had to be estimated in a biologically plausible way. In previous experiments (unpublished data) [28], we observed the first RRT-PCR positive signal in oropharyngeal fluid 1 day p.i. of the highly virulent strain Brescia and 3 days p.i. of the moderately virulent strain Paderborn and the low virulent strain Zoelen. For each contact animal, this period (1 or 3 days) was subtracted from the moment the first positive RRT-PCR-signal in oropharyngeal fluid was observed to obtain the moment of infection.

Furthermore, for the estimation of $\beta$ and $R_{0}$ the start and end of the infectious period of infected animals needed to be determined. The periods of infectiousness were estimated using three different assumptions. For the start and end of the infectious period, the assumption was made that infectiousness had coincided with the following: (1) virus excretion in faeces, (2) virus excretion in faeces and/or oropharyngeal fluid, (3) viraemia. Virus excretion and viraemia were determined by virus isolation. We assumed that any negative test result both preceded and followed by a positive test result was false negative.

\section{RESULTS}

\subsection{Infection and transmission}

\subsubsection{Zoelen}

None of the pigs inoculated with the Zoelen strain showed fever or clinical symptoms, but infection was confirmed by leukopenia, viraemia, serology and RRT-PCR positive tonsils (Tab. I). Infectious virus, as determined by virus titration, was detected mainly in oropharyngeal fluid (Tabs. II and III). No virus transmission to any of the contact pigs was observed, since no fever, leukopenia, viraemia, and antibodies were detected. The virus isolation and RRTPCR on oropharyngeal fluid and faeces samples were also negative. Furthermore, no viral RNA, as determined by RRT-PCR, was detected in the tonsils.

\subsubsection{Paderborn low inoculation dose}

None of the pigs inoculated with a dose of $10^{2}$ TCID $_{50}$ became infected. This was determined by the absence of clinical symptoms, fever, leukopenia, viraemia, and antibodies in 
Table I. Clinical symptoms, blood parameters, serology, virus isolation and RRT-PCR results.

\begin{tabular}{|c|c|c|c|c|c|c|c|}
\hline Virus strain and dose $\mathrm{e}^{\mathrm{a}}$ & $\mathrm{CS}^{\mathrm{b}}$ & Fever $^{\mathrm{c}}$ & Leukopenia $^{\mathrm{d}}$ & VI leukocytes ${ }^{\mathrm{e}}$ & ELISA $^{\mathrm{f}}$ & NPLA titre ${ }^{g}$ & RRT-PCR on tonsils \\
\hline \multicolumn{8}{|l|}{ Zoelen $-10^{5} \mathrm{TCID}_{50}$} \\
\hline I & no & no & yes & $5-7$ & + & 640 & + \\
\hline I & no & no & no & $5-7$ & + & 320 & + \\
\hline I & no & no & yes & $5-7$ & + & 320 & + \\
\hline \multicolumn{8}{|c|}{ Paderborn middle $-10^{3.5} \mathrm{TCID}_{50}$} \\
\hline I & yes & no & yes & $7-12$ & + & 80 & + \\
\hline I & yes & yes & yes & $5-23^{\dagger}$ & + & 20 & + \\
\hline I & yes & yes & yes & $5-35$ & + & $<5$ & + \\
\hline $\mathrm{C}$ & yes & yes & yes & $17-35$ & + & $<5$ & + \\
\hline $\mathrm{C}$ & yes & yes & yes & $14-35$ & + & 5 & + \\
\hline $\mathrm{C}$ & yes & yes & yes & $12-35$ & + & $<5$ & + \\
\hline $\mathrm{C}$ & yes & yes & yes & $17-29^{\dagger}$ & + & 20 & + \\
\hline $\mathrm{C}$ & yes & yes & yes & $14-35$ & + & $<5$ & + \\
\hline $\mathrm{C}$ & yes & yes & yes & $14-35$ & + & $<5$ & + \\
\hline $\mathrm{C}$ & yes & yes & yes & $17-28$ & + & 80 & + \\
\hline \multicolumn{8}{|c|}{ Paderborn high $-10^{5} \mathrm{TCID}_{50}$} \\
\hline I & yes & yes & yes & $5-32^{\dagger}$ & - & $<5$ & + \\
\hline I & yes & yes & yes & $3-21$ & + & 20 & + \\
\hline I & yes & yes & yes & $3-21^{\dagger}$ & - & $<5$ & + \\
\hline $\mathrm{C}$ & yes & yes & yes & $17-35$ & + & 10 & + \\
\hline $\mathrm{C}$ & yes & yes & yes & $17-35$ & + & $<5$ & + \\
\hline $\mathrm{C}$ & yes & yes & yes & $17-35$ & + & $<5$ & + \\
\hline $\mathrm{C}$ & yes & yes & yes & $17-24$ & + & 80 & + \\
\hline $\mathrm{C}$ & yes & yes & yes & $14-21$ & + & 20 & + \\
\hline $\mathrm{C}$ & yes & yes & yes & $10-35$ & - & $<5$ & + \\
\hline $\mathrm{C}$ & yes & yes & yes & $14-31^{\dagger}$ & + & 5 & + \\
\hline \multicolumn{8}{|l|}{ Brescia $-10^{2.5} \mathrm{TCID}_{50}$} \\
\hline I & yes & yes & yes & $3-14^{\dagger}$ & + & $<5$ & + \\
\hline I & yes & yes & yes & $3-13^{\dagger}$ & - & $<5$ & + \\
\hline I & yes & yes & yes & $3-11^{\dagger}$ & - & $<5$ & + \\
\hline $\mathrm{C}$ & yes & yes & yes & $10-21^{\dagger}$ & + & $<5$ & + \\
\hline $\mathrm{C}$ & yes & yes & no & $10-13^{\dagger}$ & - & $<5$ & + \\
\hline $\mathrm{C}$ & yes & yes & yes & $10-14^{\dagger}$ & - & $<5$ & + \\
\hline $\mathrm{C}$ & yes & yes & yes & $10-21^{\dagger}$ & + & $<5$ & + \\
\hline $\mathrm{C}$ & yes & yes & yes & $10-18^{\dagger}$ & + & $<5$ & + \\
\hline C & yes & yes & yes & $10-13^{\dagger}$ & - & $<5$ & + \\
\hline $\mathrm{C}$ & yes & yes & yes & $10-12^{\dagger}$ & - & $<5$ & + \\
\hline
\end{tabular}

${ }^{\dagger}$ Day of death or euthanasia (p.i.).

${ }^{\text {a }}$ Contact pigs of the Zoelen trial and pigs from the Paderborn low inoculation dose trial were not included in the table since none of the tests showed a positive result.

${ }^{\mathrm{b}}$ Clinical symptoms: $\mathrm{CS}>2$.

${ }^{\mathrm{c}}$ Body temperature for 2 or more consecutive days $>40{ }^{\circ} \mathrm{C}$.

${ }^{\mathrm{d}}$ Leukopenia: $<10 \times 10^{9}$ leukocytes/L blood.

${ }^{\mathrm{e}}$ Interval in days p.i. when virus isolation on leukocytes were positive.

${ }^{\mathrm{f}}$ ELISA on serum samples: + positive, - negative.

${ }^{g}$ NPLA-titre in serum samples. 
Table II. Infectious virus titres in oropharyngeal fluid $\left(\log _{10} \mathrm{TCID} 50 / \mathrm{mL}\right)$, in grey RRT-PCR positive samples.

\begin{tabular}{|c|c|c|c|c|c|c|c|c|c|c|c|c|c|c|c|c|c|c|c|c|c|c|}
\hline \multirow{2}{*}{$\begin{array}{r}\text { Virus } \\
\text { strain/ } \\
\text { dose }^{\text {a }}\end{array}$} & \multicolumn{22}{|c|}{ Days post-inoculation } \\
\hline & 0 & 3 & 4 & 5 & 6 & 7 & 8 & 10 & 11 & 12 & 13 & 14 & 15 & 17 & 19 & 21 & 24 & 26 & 28 & 31 & 33 & 35 \\
\hline \multicolumn{23}{|c|}{ Zoelen $-10^{5}$ TCID 50} \\
\hline I & - & $-{ }^{\mathrm{b}}$ & $1.9^{\mathrm{c}}$ & 3.4 & 2.7 & 2.9 & - & - & 1.4 & - & - & - & - & - & - & - & - & - & - & - & - & - \\
\hline I & - & 1.7 & 3.2 & 2.9 & 3.7 & 3.2 & - & - & - & - & - & - & - & - & - & - & - & - & - & - & - & - \\
\hline $\mathrm{I}$ & - & - & - & - & - & 0.9 & - & - & 2.4 & 2.2 & - & - & - & - & - & - & - & - & - & - & - & - \\
\hline \multicolumn{23}{|c|}{ Paderborn middle $-10^{3.5}$ TCID 50} \\
\hline I & - & - & - & - & - & 1.1 & - & - & 3.1 & - & - & - & - & - & - & - & - & - & - & - & - & - \\
\hline I & - & - & - & - & - & 2.1 & - & - & 4.6 & 0.4 & - & - & - & 5.9 & 4.7 & - & $\dagger$ & & & & & \\
\hline I & - & - & - & 0.9 & - & 2.4 & - & 0.4 & 5.1 & 4.7 & 6.4 & 7.4 & 6.4 & 6.9 & 4.4 & - & 4.7 & 6.4 & 5.7 & 4.7 & 6.7 & 6.4 \\
\hline $\mathrm{C}$ & - & - & - & - & - & - & - & - & - & - & - & - & - & 2.4 & - & - & 5.2 & 5.4 & 4.9 & 5.9 & 5.9 & 7.2 \\
\hline $\mathrm{C}$ & - & - & - & - & - & - & - & - & 0.4 & - & - & 1.9 & - & 2.7 & - & - & 5.2 & 4.9 & 4.2 & 4.4 & 5.4 & 6.9 \\
\hline $\mathrm{C}$ & - & - & - & - & - & - & - & - & $\overline{0.6}$ & - & - & - & - & $\overline{4.4}$ & - & - & 5.9 & 6.9 & 6.4 & 3.7 & 4.9 & 6.9 \\
\hline $\mathrm{C}$ & - & - & - & - & - & - & - & - & - & - & - & - & - & 2.4 & 1.7 & - & 4.7 & 6.9 & 6.4 & $\dagger$ & & \\
\hline $\mathrm{C}$ & - & - & - & - & - & - & - & - & - & - & - & - & - & 3.7 & 2.9 & - & 5.2 & 5.9 & 4.7 & 4.9 & 5.2 & 6.2 \\
\hline $\mathrm{C}$ & - & - & - & - & - & - & - & - & - & - & - & - & - & 2.2 & - & - & 5.7 & 6.4 & 6.9 & 5.7 & 5.9 & 6.9 \\
\hline $\mathrm{C}$ & - & - & - & - & - & - & - & - & - & - & - & - & - & 3.2 & - & 1.2 & 1.9 & 3.4 & 0.4 & - & 0.9 & 0.4 \\
\hline \multicolumn{23}{|c|}{ Paderborn high $-10^{5}$ TCIDs0 } \\
\hline I & - & - & 0.4 & 0.9 & 0.6 & - & - & - & 5.4 & 5.1 & - & - & 1.4 & 5.7 & 1.4 & 4.4 & 5.9 & 6.2 & 5.2 & 4.1 & $\dagger$ & \\
\hline I & - & - & - & 0.9 & - & - & - & - & 3.9 & 3.4 & - & - & - & 4.4 & - & - & - & 2.2 & 4.9 & - & - & - \\
\hline I & - & - & 1.6 & 2.4 & - & - & - & - & 5.4 & 4.1 & 2.1 & - & 2.1 & 5.9 & 2.9 & $\dagger$ & & & & & & \\
\hline $\mathrm{C}$ & - & - & - & - & - & - & - & - & - & - & - & - & - & - & - & 5.4 & 5.2 & 6.4 & 4.2 & 6.2 & 7.4 & 7.2 \\
\hline $\mathrm{C}$ & - & - & - & - & - & - & - & - & - & 0.4 & - & - & - & 2.2 & - & - & 3.4 & 3.1 & 3.7 & 5.9 & 6.7 & 6.9 \\
\hline $\mathrm{C}$ & - & - & - & - & - & - & - & - & - & - & - & - & - & - & - & 0.4 & 2.6 & 4.9 & 4.4 & 6.4 & 4.9 & 6.4 \\
\hline $\mathrm{C}$ & - & - & - & - & - & - & - & - & - & 2.4 & - & - & - & - & - & - & - & - & - & - & - & - \\
\hline $\mathrm{C}$ & - & - & - & - & - & - & - & - & 0.4 & - & - & - & - & - & - & - & - & - & - & - & - & - \\
\hline $\mathrm{C}$ & - & - & - & - & - & - & - & - & - & 0.4 & - & - & - & 3.2 & 2.4 & 5.2 & 5.9 & 6.9 & 6.7 & 6.9 & 6.7 & 7.4 \\
\hline $\mathrm{C}$ & - & - & - & - & - & - & - & - & - & 0.4 & - & - & - & - & 0.6 & 4.4 & 5.2 & 6.7 & 6.2 & $\dagger$ & & \\
\hline \multicolumn{23}{|c|}{ Brescia $-10^{2.5}$ TCID 50} \\
\hline I & - & 2.9 & 3.4 & 3.7 & 3.9 & 4.2 & 3.9 & 3.7 & 5.2 & 4.9 & 3.9 & - & $\dagger$ & & & & & & & & & \\
\hline I & - & 3.2 & 3.2 & 3.2 & 3.2 & 2.2 & -1 & 4.7 & 5.7 & 5.4 & 5.7 & $\dagger$ & & & & & & & & & & \\
\hline I & - & 2.9 & 2.9 & 3.7 & 4.2 & - & 3.9 & 5.2 & 6.2 & $\dagger$ & & & & & & & & & & & & \\
\hline $\mathrm{C}$ & - & - & - & - & - & - & - & 1.7 & 5.2 & 4.7 & 4.9 & - & 4.4 & 5.7 & 4.9 & 2.4 & $\dagger$ & & & & & \\
\hline $\mathrm{C}$ & - & - & - & - & - & - & - & - & 3.9 & 1.9 & 3.9 & $\dagger$ & & & & & & & & & & \\
\hline $\mathrm{C}$ & - & - & - & - & -1 & - & -1 & 2.4 & 4.4 & 2.2 & 4.4 & - & $\dagger$ & & & & & & & & & \\
\hline $\mathrm{C}$ & - & - & - & - & - & - & 1.9 & 2.7 & 4.7 & 4.9 & 3.2 & 3.9 & 1.6 & 5.7 & 5.4 & 4.9 & $\dagger$ & & & & & \\
\hline $\mathrm{C}$ & - & - & - & - & - & - & 2.4 & - & 2.4 & 2.4 & 4.2 & - & 3.2 & 3.7 & $\dagger$ & & & & & & & \\
\hline $\mathrm{C}$ & - & - & - & - & -1 & - & - & - & 4.9 & 5.4 & 3.7 & $\dagger$ & & & & & & & & & & \\
\hline $\mathrm{C}$ & - & - & - & - & - & - & - & 2.4 & 5.2 & 4.2 & $\dagger$ & & $\dagger$ & & & & & & & & & \\
\hline
\end{tabular}

- No virus was isolated.

$\dagger$ Death or euthanasia of the pig.

${ }^{\text {a }}$ Contact pigs of the Zoelen trial and pigs from the Paderborn low inoculation dose trial werenot included in the table since none of these pigs were infected.

${ }^{\mathrm{b}}$ RRT-PCR positive samples are indicated in grey.

${ }^{\mathrm{c}} \log _{10} \mathrm{TCID} 50 / \mathrm{mL}$.

the serum. The virus isolation and RRT-PCR on oropharyngeal fluid and faeces samples were also negative. No viral RNA, as determined by RRT-PCR, was detected in the tonsils. As a consequence, no virus transmission to the contact pigs was observed either. 
Table III. Infectious virus titres in faeces $\left(\log _{10} \mathrm{TCID}_{50} / \mathrm{g}\right)$, in grey RRT-PCR positive samples.

\begin{tabular}{|c|c|c|c|c|c|c|c|c|c|c|c|c|c|c|c|c|c|c|c|c|c|c|}
\hline \multirow{2}{*}{$\begin{array}{c}\text { Virus } \\
\text { strain/ } \\
\text { dose }^{\mathrm{a}}\end{array}$} & \multicolumn{22}{|c|}{ Days post-inoculation } \\
\hline & 0 & 3 & 4 & 5 & 6 & 7 & 8 & \multicolumn{2}{|c|}{1011} & \multicolumn{2}{|c|}{1213} & \multicolumn{2}{|c|}{1415} & \multicolumn{2}{|c|}{1719} & \multicolumn{2}{|c|}{2124} & \multicolumn{2}{|c|}{2628} & \multicolumn{2}{|c|}{3133} & 35 \\
\hline \multicolumn{23}{|c|}{ Zoelen $-10^{5} \mathrm{TCID}_{50}$} \\
\hline I & - & - & - & - & $-{ }^{\mathrm{b}}$ & - & - & - & - & - & - & - & - & - & - & - & - & - & - & - & - & - \\
\hline I & - & - & - & - & - & - & - & - & - & - & - & - & - & - & - & - & - & - & - & - & - & - \\
\hline I & - & - & - & - & - & $1.4^{\mathrm{c}}$ & - & - & - & - & - & - & - & - & - & - & - & - & - & - & - & - \\
\hline \multicolumn{23}{|c|}{ Paderborn middle $-10^{3.5}$ TCID 50} \\
\hline$-\quad-$ & - & - & - & - & - & 2.9 & 2.9 & 3.4 & 2.9 & - & - & - & - & - & - & - & - & - & - & - & - & - \\
\hline I & - & - & - & 1.6 & 4.2 & 5.4 & 4.7 & 5.9 & 5.7 & 5.7 & 6.2 & 5.7 & 5.9 & 5.4 & 4.9 & $4.9 \dagger$ & & & & & & \\
\hline I & - & - & - & 1.6 & 3.9 & 5.7 & 5.2 & 6.4 & 6.7 & 5.9 & 6.7 & 5.9 & 4.6 & 5.2 & 4.4 & 4.7 & 6.4 & 5.2 & 5.7 & 4.6 & 6.1 & 6.4 \\
\hline $\mathrm{C}$ & - & - & - & - & - & - & - & - & - & - & - & - & - & - & 1.6 & 1.6 & 5.4 & 4.9 & 5.7 & 5.4 & 4.4 & 3.9 \\
\hline $\mathrm{C}$ & - & - & - & - & - & - & - & - & - & - & - & - & - & - & 3.4 & 4.7 & 5.2 & 4.4 & 3.9 & 5.9 & tox & 6.4 \\
\hline $\mathrm{C}$ & - & - & - & - & - & - & - & - & - & 3.2 & 3.2 & 4.4 & 3.4 & 3.4 & 3.4 & 4.2 & 4.2 & 3.7 & 3.7 & 3.9 & tox & 5.4 \\
\hline $\mathrm{C}$ & - & - & - & - & - & - & - & - & - & - & - & - & - & - & 4.7 & 5.9 & 4.9 & 5.2 & $5.9 \dagger$ & & & \\
\hline $\mathrm{C}$ & - & - & - & - & - & - & - & - & - & - & - & 2.9 & 3.7 & 3.4 & 4.2 & 4.9 & 3.9 & 6.4 & 3.6 & 5.7 & 5.2 & 4.9 \\
\hline $\mathrm{C}$ & - & - & - & - & - & - & - & - & - & - & - & - & - & 4.2 & 4.7 & 6.7 & 6.4 & 6.2 & 4.9 & 4.6 & 4.7 & 4.9 \\
\hline $\mathrm{C}$ & - & - & - & - & - & - & - & - & - & - & - & - & - & 3.7 & 3.9 & 4.4 & 3.4 & 3.4 & 3.4 & 2.9 & 3.2 & 3.7 \\
\hline \multicolumn{23}{|c|}{ Paderborn high $-10^{5}$ TCID 50} \\
\hline I & - & - & tox $^{\mathrm{d}}$ & 3.3 & 3.7 & 4.4 & 4.7 & 5.4 & 5.2 & 5.4 & 5.9 & 6.2 & 6.2 & 5.2 & 3.9 & 4.5 & 7.2 & 5.9 & 6.2 & $5.2 \dagger$ & & \\
\hline I & - & - & - & tox & 2.7 & 3.9 & 4.4 & 2.9 & 3.9 & - & - & 2.6 & 3.2 & 3.9 & 4.7 & 3.9 & 3.4 & 4.2 & 3.9 & - & - & - \\
\hline I & - & - & - & - & 2.9 & 3.7 & 4.7 & 6.7 & 6.9 & 4.2 & 6.4 & 3.2 & 6.0 & 6.9 & $5.9 \dagger$ & & & & & & & \\
\hline $\mathrm{C}$ & - & - & - & - & - & - & - & - & - & - & - & - & - & - & 4.2 & 4.4 & 3.9 & 5.9 & 7.3 & 4.7 & 4.2 & 6.2 \\
\hline $\mathrm{C}$ & - & - & - & - & - & - & - & - & - & - & - & - & - & 4.2 & 3.4 & 4.9 & 4.9 & 5.2 & 5.2 & 6.0 & 4.4 & 5.4 \\
\hline $\mathrm{C}$ & - & - & - & - & - & - & - & - & - & - & - & - & - & - & 3.9 & 5.9 & 5.9 & 3.9 & 6.8 & 4.9 & 5.9 & 5.1 \\
\hline $\mathrm{C}$ & - & - & - & - & - & - & - & - & - & - & - & - & - & 1.9 & 4.2 & - & - & - & - & - & - & - \\
\hline $\mathrm{C}$ & - & - & - & - & - & - & - & - & - & - & - & - & - & 3.4 & - & - & - & - & - & - & - & - \\
\hline $\mathrm{C}$ & - & - & - & - & - & - & - & - & - & - & 3.2 & 3.4 & 4.9 & 4.7 & 4.2 & 4.4 & 5.4 & 4.9 & 4.7 & 3.2 & 3.9 & 4.4 \\
\hline $\mathrm{C}$ & - & - & - & - & - & - & - & - & - & - & - & - & 3.7 & 4.2 & 3.9 & 5.4 & 5.9 & 5.4 & $5.9 \dagger$ & & & \\
\hline \multicolumn{23}{|c|}{ Brescia $-10^{2.5}$ TCID 50} \\
\hline I & - & - & - & 2.9 & 3.1 & 2.9 & 3.4 & 5.2 & 4.9 & 6.7 & 5.4 & $4.5 \dagger$ & & & & & & & & & & \\
\hline I & - & - & 1.6 & 2.6 & 2.4 & 3.1 & 3.7 & 4.7 & 4.4 & 4.4 & $4.4 \dagger$ & & & & & & & & & & & \\
\hline I & - & - & - & 1.6 & 4.1 & 4.7 & 2.9 & 3.9 & $5.7 \dagger$ & & & & & & & & & & & & & \\
\hline $\mathrm{C}$ & - & - & - & - & - & - & - & 3.9 & 4.8 & 4.7 & 4.4 & 5.5 & 5.5 & 2.7 & 2.7 & $4.2 \dagger$ & & & & & & \\
\hline $\mathrm{C}$ & - & - & - & - & - & - & - & 3.2 & 4.2 & 5.2 & $3.9+$ & & & & & & & & & & & \\
\hline $\mathrm{C}$ & - & - & - & - & - & - & - & 3.4 & 4.8 & 4.7 & 2.7 & $4.0 \dagger$ & & & & & & & & & & \\
\hline $\mathrm{C}$ & - & - & - & - & - & - & - & 4.9 & 3.7 & 5.4 & 4.7 & 6.4 & 4.5 & 3.9 & 5.7 & $4.2 \dagger$ & & & & & & \\
\hline $\mathrm{C}$ & - & - & - & - & - & - & - & - & 3.9 & 2.7 & 5.2 & 3.2 & 4.4 & $4.2 \dagger$ & & & & & & & & \\
\hline $\mathrm{C}$ & - & - & - & - & - & - & - & 3.4 & 5.1 & 4.4 & $4.4 \dagger$ & & & & & & & & & & & \\
\hline $\mathrm{C}$ & - & - & - & - & - & - & - & 3.4 & 3.7 & 2.7 & $\dagger$ & & & & & & & & & & & \\
\hline
\end{tabular}

- No virus was isolated.

$\dagger$ Death or euthanasia of the pig.

${ }^{a}$ Contact pigs of the Zoelen trial and pigs from the Paderborn low inoculation dose trial (102 $\left.\mathrm{TCID}_{50}\right)$ were not included in the table since none of these pigs were infected.

${ }^{\mathrm{b}}$ RRT-PCR positive sample are indicated in grey.

${ }^{\mathrm{c}} \log _{10}$ TCID $50 / \mathrm{g}$.

d Toxic sample.

\subsubsection{Paderborn middle inoculation dose}

All pigs inoculated with a dose of $10^{3.5}$ $\mathrm{TCID}_{50}$ became infected and developed clinical symptoms, leukopenia, viraemia, E2-antibodies
(ELISA) and were RRT-PCR positive in the tonsils. Infectious virus was detected in oropharyngeal fluid and faeces from day 5 p.i. A wide variety of clinical symptoms were observed in these pigs. Two pigs showed severe clinical 
symptoms (CS of 17 and 21), while one pig showed only mild clinical signs (CS of 3 ) and no fever. One inoculated pig died at day 23 p.i. All contact pigs became infected and developed fever, clinical signs, leukopenia, viraemia and E2-antibodies. Viral RNA was generally detected first in oropharyngeal fluid and maximum 7 days later in faeces. In oropharyngeal fluid, viral RNA was first detected either on day 8 or 10 p.i. Observed clinical signs in the most severely affected pigs were depression, loss of appetite, emaciation, increased frequency of breathing, cramps, paralysis of the hindquarters, inability to stand up, haemorrhages in the skin, and diarrhoea. One contact pig died at day 29 p.i.

\subsubsection{Paderborn high inoculation dose}

All pigs inoculated with a dose of $10^{5}$ TCID $_{50}$ became infected and developed fever, clinical symptoms, leukopenia and viraemia. Infectious virus was detected from day 4 p.i. in oropharyngeal fluid and from day 5 p.i. in faeces. Fever started one day earlier than in the pigs inoculated with the middle dose. Two inoculated pigs died at days 21 and 32 p.i. Only the inoculated pig that recovered from the infection developed E2-antibodies higher than the cut-off of $30 \%$ inhibition. Although the other two pigs showed an increase in E2-antibody titre of $19 \%$ and $20 \%$ inhibition, they died before the antibody titre could reach the cutoff. All the contact pigs became infected and developed fever, clinical symptoms, leukopenia, and viraemia. Viral RNA was detected in oropharyngeal fluid between days 8 and 11 p.i. Six of the seven contact pigs developed E2-antibodies higher than the cut-off, including one pig that died at day 31 p.i. The observed clinical signs in the most severely affected pigs were comparable to (contacts of) pigs inoculated with the middle dose.

\subsubsection{Brescia}

All pigs inoculated with the Brescia strain became infected and developed fever, clinical signs, leukopenia, and viraemia. Infectious virus was already detected on the first sampling day (day 3 p.i.) in oropharyngeal fluid. In faeces, infectious virus was detected from day 4 p.i. All inoculated pigs died between days 12 and 15 p.i. One pig developed E2-antibodies higher than the cut-off, while the E2 ELISA of one other pig suggests an increase in E2-antibodies (17\% inhibition), although the level remained under the cut-off. The contact pigs developed fever and clinical signs, and 6 of the 7 contact pigs developed leukopenia. The majority of the contact pigs did not develop E2-antibodies higher than the cut-off. Viral RNA was detected in oropharyngeal fluid between days 4 and 6 p.i. All contact pigs died between days 13 and 22 p.i. The observed clinical signs were severe depression, emaciation, loss of appetite, cramps, ataxia, inability to stand up, large haemorrhages in the skin, and diarrhoea.

\subsection{Differences in virus excretion between strains}

All contact infections took place within the first five days of virus excretion by the inoculated pigs. Figure 1 shows the total virus excretion during these days by the inoculated pigs, which was expressed by the cumulative excretion (against time). Pigs inoculated with the Brescia strain excreted the highest amount of virus in oropharyngeal fluid, but this was only significantly different until the second day of virus excretion from pigs inoculated with the middle dose of the Paderborn strain. After the second day, the differences between the strains were not significant. Pigs inoculated with the Zoelen strain excreted significantly lower amounts of virus in faeces than pigs inoculated with the Paderborn and Brescia strain. No significant differences in virus excretion in faeces were observed between pigs inoculated with the middle dose of the Paderborn strain, the high dose of the Paderborn strain or the Brescia strain.

\subsection{Quantification of transmission parameters}

The transmission rate $\beta$, the infectious period $T i$, the standard deviation of the infectious period and the reproduction ratio $R_{0}$ for all three 

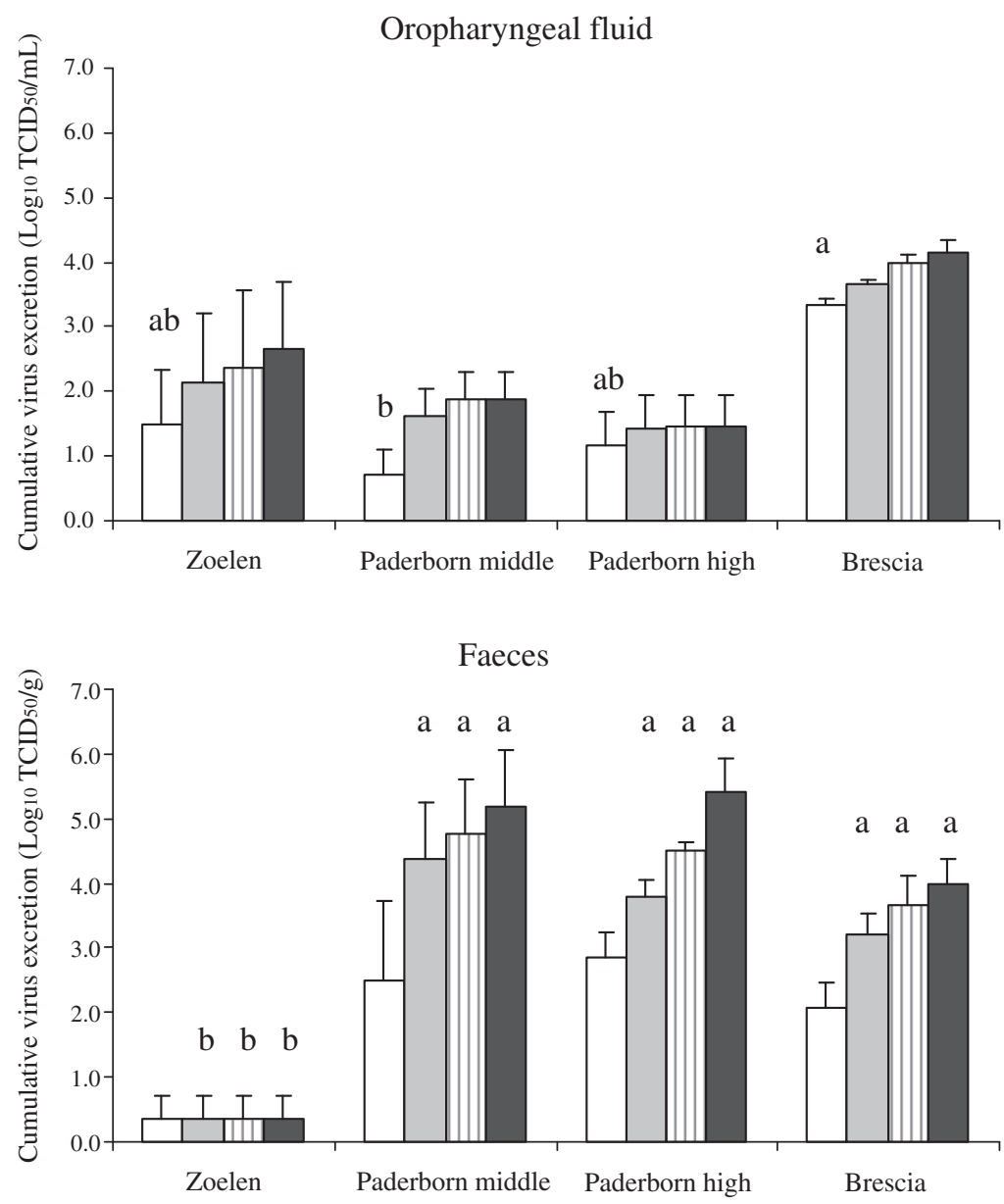

Figure 1. Total virus excretion (cumulative virus excretion (against time)) of the three inoculated pigs in faeces and oropharyngeal fluid until the second day (white bar), third day (grey bar), fourth day (striped bar) or fifth day (black bar) of virus excretion (depending on strain and sample type, the first day of virus excretion was observed between days 3 and 5 p.i.). a,b: Bars of the same colour with no common letter differ significantly $(p<0.05)$. Error bars represent standard error of the mean (SEM).

assumptions on the infectiousness of pigs are shown in Table IV. The $\beta$ of the Zoelen strain was estimated to be 0 per day, since no virus transmission occurred. The $\beta$ of the Paderborn middle inoculation dose was slightly higher than that of the Paderborn high inoculation dose, although the difference was only significant when the infectious period was assumed to coincide with virus excretion in faeces and/or oropharyngeal fluid. The $\beta$ 's of the Paderborn and Brescia strain were comparable, except under the assumption that infectiousness coincided with virus excretion in faeces only. In that case the $\beta$ for strain Brescia was significantly higher.

The duration of virus excretion $T i$ was significantly higher for both inoculation doses of the Paderborn strain than for the Zoelen or Brescia strain, independent of the assumptions.

The reproduction ratio $R_{0}$ of the Zoelen strain was estimated to be $0 \quad(0-0.925)$. For the Paderborn strain, the $\mathrm{R}_{0}$ was significantly higher when the middle dose (148 
Table IV. Estimation of transmission parameters with $95 \%$ confidence intervals, based on different assumptions on the infectious period of pigs.

\begin{tabular}{|c|c|c|c|c|c|c|c|}
\hline \multirow[t]{2}{*}{ Transmission parameter } & \multicolumn{7}{|c|}{ Virus strain and inoculation dose ${ }^{1}$} \\
\hline & \multicolumn{2}{|c|}{$\begin{array}{c}\text { Zoelen } \\
-10^{5} \mathrm{TCID}_{50}\end{array}$} & $\begin{array}{c}\text { Paderborn middle } \\
-10^{3.5} \text { TCID }_{50}\end{array}$ & \multicolumn{2}{|c|}{$\begin{array}{c}\text { Paderborn high } \\
-10^{5} \mathrm{TCID}_{50}\end{array}$} & \multicolumn{2}{|c|}{$\begin{array}{c}\text { Brescia } \\
-10^{2.5} \mathrm{TCID}_{50}\end{array}$} \\
\hline \multicolumn{8}{|l|}{$\beta\left(\right.$ day $\left.^{-1}\right)$} \\
\hline Assumption 1 (faeces) ${ }^{2}$ & $0^{\mathrm{c}}$ & $(0-2.74)$ & $5.38^{\mathrm{b}}(2.11-12.2)$ & $2.83^{\mathrm{b}, \mathrm{c}}$ & $(1.17-5.84)$ & $27.5^{\mathrm{a}}$ & $(10.2-63.0)$ \\
\hline Assumption $2(\mathrm{OPF} / \text { faeces })^{3}$ & $0^{\mathrm{c}}$ & $(0-0.144)$ & $5.38^{\mathrm{a}}(2.11-12.2)$ & $1.62^{\mathrm{b}}$ & $(0.685-3.23)$ & $2.07^{\mathrm{a}, \mathrm{b}}$ & $(0.881-4.05)$ \\
\hline Assumption 3 (viraemia) $^{4}$ & $0^{\mathrm{b}}$ & $(0-0.203)$ & $3.23^{\mathrm{a}}(1.33-6.74)$ & $1.14^{\mathrm{a}}$ & $(0.486-2.24)$ & $3.00^{\mathrm{a}}$ & $(1.27-5.96)$ \\
\hline \multicolumn{8}{|l|}{$T i$ (day) } \\
\hline Assumption 1 (faeces) & -5 & $(---)$ & $26.2^{\mathrm{a}}(17.4-42.6)$ & $21.2^{\mathrm{a}}$ & $(13.4-34.5)$ & $7.39^{\mathrm{b}}$ & $(5.54-9.99)$ \\
\hline Assumption 2 (OPF/faeces) & $6.33^{\mathrm{b}}$ & $(4.69-8.69)$ & $27.5^{\mathrm{a}}(18.4-43.7)$ & $22.2^{\mathrm{a}}$ & $(16.2-31.9)$ & $8.47^{\mathrm{b}}$ & $(6.17-11.8)$ \\
\hline Assumption 3 (viraemia) & - & $(---)$ & $24.4^{\mathrm{a}}(17.5-36.8)$ & $21.8^{\mathrm{a}}$ & $(16.7-30.3)$ & $8.38^{\mathrm{b}}$ & $(6.34-11.2)$ \\
\hline \multicolumn{8}{|l|}{$\mathrm{SD}^{6}$ of $T i$ (day) } \\
\hline Assumption 1 (faeces) & - & $(---)$ & $12.8^{\mathrm{a}}(7.33-21.6)$ & $13.0^{\mathrm{a}}$ & $(8.14-20.9)$ & $3.22^{\mathrm{b}}$ & $(2.15-5.67)$ \\
\hline Assumption 2 (OPF/faeces) & $1.23^{\mathrm{b}}$ & $(0.648-3.82)$ & $13.2^{\mathrm{a}}(7.63-21.8)$ & $9.32^{\mathrm{a}}$ & $(5.81-16.5)$ & $4.06^{\mathrm{b}}$ & $(2.71-7.11)$ \\
\hline Assumption 3 (viraemia) & - & $(---)$ & $10.6^{\mathrm{a}}(6.27-18.9)$ & $7.99^{\mathrm{a}}$ & $(4.90-14.8)$ & $3.54^{\mathrm{b}}$ & $(2.36-6.13)$ \\
\hline \multicolumn{8}{|l|}{$\mathrm{R}_{0}$} \\
\hline Assumption 1 (faeces) & - & $(---)$ & $141^{\mathrm{a}} \quad(50.6-367)$ & $60.0^{\mathrm{a}}$ & $(22.5-145)$ & $203^{\mathrm{a}}$ & $(73.2-488)$ \\
\hline Assumption 2 (OPF/faeces) & $0^{\mathrm{c}}$ & $(0-0.925)$ & $148^{\mathrm{a}} \quad(53.8-382)$ & $35.9^{\mathrm{b}}$ & $(14.5-77.6)$ & $17.5^{\mathrm{b}}$ & $(7.13-36.9)$ \\
\hline Assumption 3 (viraemia) & - & $(---)$ & $78.8^{\mathrm{a}}(30.7-181)$ & $24.8^{\mathrm{a}}$ & $(10.2-52.0)$ & $25.1^{\mathrm{a}}$ & $(10.3-52.8)$ \\
\hline
\end{tabular}

${ }^{\mathrm{a}-\mathrm{c}}$ Means within rows with no common superscript differ significantly.

${ }^{1}$ Pigs from the low inoculation dose trial $\left(10^{2} \mathrm{TCID}_{50}\right)$ were not included in the table since none of the pigs were infected.

${ }^{2}$ Start and end of the infectious period coincided with virus excretion in faeces.

${ }^{3}$ Start and end of the infectious period coincided with virus excretion in faeces and/or oropharyngeal fluid.

${ }^{4}$ Start and end of the infectious period coincided with viraemia.

${ }^{5}$ The $95 \%$ interval could not be determined due to lack of (variation in) data.

${ }^{6}$ Standard deviation.

(53.8-382)) was used for inoculation instead of the high dose (35.9 (14.5-77.6)), under the assumption that infectiousness coincided with virus excretion in faeces and/or oropharyngeal fluid. The $\mathrm{R}_{0}$ was also significantly higher for the middle dose of the Paderborn strain than for the Brescia strain (17.5 (7.13-36.9)). Under the other assumptions, there were no significant difference between both inoculation doses of the Paderborn strain or the Brescia strain.

\section{DISCUSSION}

This study quantified transmission parameters of three strains of different virulence; a low, moderately and highly virulent strain.
The transmission parameters were estimated using the maximum likelihood estimation method, which takes into account the time course of the experimental epidemic. Different assumptions were used to determine the period of infectiousness. These assumptions turned out to be rather crucial in estimating the transmission parameters $\beta$ and $R_{0}$.

Transmission parameters of moderately virulent strains like the Paderborn strain have been quantified with the maximum likelihood estimation method before. For the Paderborn strain, a $\beta$ of 0.65 per day $(0.40-1.1)$ was estimated by Klinkenberg ${ }^{1}$. Using the same method Klinkenberg applied, we actually found the same $\beta$ of 0.65 per day $(0.37-1.1)$ for the Paderborn strain with the data of our study (results not shown). 
This shows that the estimation of the $\beta$ for the same strain is reproducible, when using the same assumptions. For our study, different observations were used to determine transmission parameters, which will be discussed in more detail below.

First of all, we used another matrix (oropharyngeal fluid instead of blood) and diagnostic tool (RRT-PCR instead of VI) to determine the moment of infection of contact pigs. Using oropharyngeal fluid instead of blood as a matrix seems biologically more appropriate, since the virus replicates first in the tonsil and pharyngeal region, after which it spreads throughout the body. Viraemia occurs at a later stage of the infection at a moment when secretions from the oropharyngeal region can already contain infectious virus [28]. The use of the RRT-PCR instead of the virus isolation will improve the determination of the moment of infection of the contact pigs, since the RRT-PCR has a higher sensitivity than virus isolation $[6,18,26]$. Between pigs infected with the same strain, smaller differences exist in the moment after infection that the RRT-PCR on oropharyngeal swabs becomes positive than the virus isolation on blood samples is positive $[24,28]$ (this study).

Secondly, the start of the infectious period of pigs was determined by the first detection of infectious virus in faeces, oropharyngeal fluid or leukocytes (viraemia). The presence of infectious virus in secretions and excretions might be a better indicator of infectiousness of the pig than viraemia, since virus excretion may not coincide with viraemia [28]. In the present study, we used faeces and oropharyngeal fluid. Faeces are excreted in large amounts in the environment and may be the main source of infectious virus from an infected pig [28]. However, especially in the first days after infection, when virus cannot yet be detected from faeces, virus from other secretions and excretions, like from the oronasal region, may contribute in a relevant way to virus transmission as well. In the present study, oropharyngeal fluid was used as a matrix to detect virus first, based on previous studies [28]. However, it cannot be excluded that virus excretion occurs even earlier in other secretions not tested in this experiment.
Differences were observed between the strains in $\beta$. The $\beta$ of the Paderborn strain and Brescia strain were always significantly higher that the $\beta$ of the Zoelen strain. The pigs inoculated with the Zoelen strain did not transmit the virus to the contact pigs at all. This was not expected since this strain was isolated in 1975 from foetuses of a "carrier sow" during a field outbreak $^{2}$. In several experimental studies $^{3}$ [28], virus titres in blood and secretions and excretions were always low, which could explain the inability of this strain to transmit to contact pigs in the present experiment. This strain was, however, successful in transplacental transmission [5]. Persistently infected piglets, excreting high quantities of virus, might have been a way for this strain to maintain itself in the field. Besides, this strain has been cell passaged before inoculation of the pigs in the present experiment, which could also have reduced the virulence.

Between the Paderborn and Brescia strains, the difference in $\beta$ depended on the assumptions on the start and duration of the infectious period of the pigs. Assuming that biologically the most appropriate way to determine whether a pig is infectious, is the detection of infectious virus from faeces and/or oropharyngeal fluid, no significant differences between the Paderborn and Brescia strains in $\beta$ (and virus excretion) were observed. These results were not unexpected. In a previous study on virus excretion, it was shown that CSFV excretion is dependent on the strain and the clinical appearance of infection [28]. In the group of pigs infected with the Paderborn strain, both chronically and acutely infected pigs were observed. Together, these pigs did not excrete amounts

\footnotetext{
${ }^{2}$ Van Oirschot J.T., Congenital infections with a moderately virulent swine fever virus. Persistent and inapparent infections with swine fever virus of low virulence. Their effects on the immune system, Ph.D. thesis University of Utrecht, The Netherlands, 1980, pp. 114-119.

${ }^{3}$ Van Oirschot J.T., Comparison of virulence of three field isolates of swine fever virus. Persistent and inapparent infections with swine fever virus of low virulence. Their effects on the immune system, $\mathrm{Ph} . \mathrm{D}$. thesis University of Utrecht, The Netherlands, 1980, pp. 120-125.
} 
of virus that were significantly different from pigs infected with the Brescia strain during the first five days of excretion, in which period all transmission events occurred (this study). Comparable excretion patterns therefore seem to result in comparable transmission rates for $\mathrm{CSF}$, at least in the early infectious period. Further research using one-to-one experiments, with single infectious pigs housed with single susceptible pigs, could further clarify the correlation between the level of virus excretion and transmission.

When the infectious period was assumed to coincide with virus excretion in faeces and/or oropharyngeal fluid, the $\mathrm{R}_{0}$ of the Paderborn strain (middle dose) was significantly higher than the $R_{0}$ of the Brescia strain. However, for strains with $\mathrm{R}_{0}$-values significantly higher than 1 , the generation interval is also an important measure in the initial phase of the outbreak [27]. The generation interval is the time between the infection moment of a pig and the moment of first infection of a contact animal by this pig. For the Paderborn strain this generation interval was 5 to 8 days, and for the Brescia strain 3 to 5 days, which would lead to exponential growth rates of $0.3 /$ day (Paderborn) and 0.4/day (Brescia) in the initial phase of the outbreak [11]. So even though the Paderborn strain has a higher $\mathrm{R}_{0}$ than the Brescia strain, the growth rate of the latter strain was higher due to its shorter generation interval.

The different doses of the Paderborn strain used for inoculation resulted in differences in transmission. The low dose of $10^{2}$ TCID $_{50}$ was not high enough to result in infection of even one of the three inoculated pigs. This was not expected since a slightly higher dose of $10^{2.5}$ TCID $_{50}$ of the Paderborn strain resulted in infection of 4 of 5 inoculated pigs ${ }^{1}$. A higher $\beta$ was observed with the middle inoculation dose than with the high dose. However, in subsequent generations, this difference will most likely disappear since there were no differences in the moment contact pigs were infected, or amounts of virus excreted by the inoculated pigs.

In conclusion, the different assumptions regarding the infectiousness of pigs resulted in differences in $\beta$ and $R_{0}$. It was concluded that biologically the most appropriate assumption is where infectiousness coincides with virus excretion in faeces and/or oropharyngeal fluid. Under this assumption it was noteworthy that $\beta$ 's were comparable for a moderately and highly virulent strain and that differences in transmission between these strains depend therefore on a different length of the infectious period and the length of the generation interval.

Acknowledgements. The authors thank Sjaak Quak, Linda Smits-Mastenbroek, Elly Wijbenga and Venice van den Berg for their technical assistance. Egil Fischer is thanked for his help with the estimation of the transmission parameters and Don Klinkenberg is thanked for his advise.

\section{REFERENCES}

[1] Colijn E.O., Bloemraad M., Wensvoort G., An improved ELISA for the detection of serum antibodies directed against classical swine fever virus, Vet. Microbiol. (1997) 59:15-25.

[2] Begon M., Bennet M., Bowers R.G., French N.P., Hazel S.M., Turner J., A clarification of transmission terms in host-microparasite models: numbers, densities and areas, Epidemiol. Infect. (2002) 129:147-153.

[3] Bouma A., de Smit A.J., de Kluijver E.P., Terpstra C., Moormann R.J.M., Efficacy and stability of a subunit vaccine based on glycoprotein E2 of classical swine fever virus, Vet. Microbiol. (1999) 66:101-114.

[4] De Jong M.C., Kimman T.G., Experimental quantification of vaccine-induced reduction in virus transmission, Vaccine (1994) 12:761-766.

[5] De Smit A.J., Bouma A., De Kluijver E.P., Terpstra C., Moormann R.J.M., Prevention of transplacental transmission of moderate-virulent classical swine fever virus after single or double vaccination with an E2 subunit vaccine, Vet. Q. (2000) 22: $150-153$.

[6] Dewulf J., Koenen F., Mintiens K., Denis P., Ribbens S., De Kruif A., Analytical performance of several classical swine fever laboratory diagnostic techniques on live animals for detection of infection, J. Virol. Methods (2004) 119:137-143.

[7] Diekmann O., Heesterbeek J.A.P., Mathematical epidemiology of infectious diseases: model building, analysis and interpretation, John Wiley and Sons, Chichester, 2000.

[8] Durand B., Davila S., Cariolet R., Mesplède A., Le Potier M.F., Comparison of viraemia- and clinicalbased estimates of within- and between-pen transmission of classical swine fever virus from three transmission experiments, Vet. Microbiol. (2009) 135:196-204. 
[9] Finney D.J., Statistical methods in biological assay, Charles Griffin \& Company Ltd., London, 1978, pp. 394-401.

[10] Greiser-Wilke I., Fritzemeier J., Koenen F., Vanderhallen H., Rutili D., De Mia G.M., et al., Molecular epidemiology of a large classical swine fever epidemic in the European Union in 1997-1998, Vet. Microbiol. (2000) 77:17-27.

[11] Keeling M.J., Rohani P., Modeling infectious diseases in humans and animals, Princeton University Press, 2008.

[12] Kaden V., Lange E., Polster U., Klopfleisch R., Teifke J.P., Studies on the virulence of two field isolates of the classical Swine Fever virus genotype 2.3 Rostock in wild boars of different age groups, J. Vet. Med. B Infect. Dis. Vet. Public Health (2004) 51:202-208.

[13] Klinkenberg D., De Bree J., Laevens H., De Jong M.C.M., Within- and between-pen transmission of classical swine fever virus: a new method to estimate the basic reproduction ratio from transmission experiments, Epidemiol. Infect. (2002) 128: 293-299.

[14] Laevens H., Koenen F., Deluyker H., Berkvens D., De Kruif A., An experimental infection with classical swine fever virus in weaner pigs. I. Transmission of the virus, course of the disease, and antibody response, Vet. Q. (1998) 2:41-45.

[15] Laevens H., Koenen F., Deluyker H., De Kruif A., Experimental infection of slaughter pigs with classical swine fever virus: transmission of the virus, course of the disease and antibody response, Vet. Rec. (1999) 145:243-248.

[16] Meuwissen M.P., Horst S.H., Huirne R.B., Dijkhuizen A.A., A model to estimate the financial consequences of classical swine fever outbreaks: principles and outcomes, Prev. Vet. Med. (1999) 42:249-270.

[17] Mittelholzer C., Moser C., Tratschin J., Hofmann M.A., Analysis of classical swine fever virus replication kinetics allows differentiation of highly virulent from avirulent strains, Vet. Microbiol. (2000) 74: 293-308.

[18] Oude Ophuis R.J.A., Morrissy C.J., Boyle D.B., Detection and quantitative pathogenesis study of classical swine fever virus using a real time RT-PCR assay, J. Virol. Methods (2006) 131:78-85.

[19] Ressang A.A., Studies on the pathogenesis of hog cholera. I. Demonstration of hog cholera virus subsequent to oral exposure, Zentralbl. Veterinarmed. B (1973) 20:256-271.

[20] Ribbens S., Dewulf J., Koenen F., Laevens H., Mintiens K., De Kruif A., An experimental infection (II) to investigate the importance of indirect classical swine fever virus transmission by excretions and secretions of infected weaner pigs, J. Vet. Med. B Infect. Dis. Vet. Public Health (2004) 51:438-442.

[21] Ribbens S., Dewulf J., Koenen F., Maes D., De Kruif A., Evidence of indirect transmission of classical swine fever virus through contacts with people, Vet. Rec. (2007) 160:687-690.

[22] Terpstra C., Bloemraad M., Gielkens A.L.J., The neutralizing peroxidase-linked assay for detection of antibody against swine fever virus, Vet. Microbiol. (1984) 9:113-120.

[23] Uttenthal A., Le Potier M.F., Romero L., De Mia G.M., Floegel-Niesmann G., Classical swine fever (CSF) marker vaccine. Trial I. Challenge studies in weaner pigs, Vet. Microbiol. (2001) 83:85-106.

[24] Uttenthal Å., Storgaard T., Oleksiewicz M.B., De Stricker K., Experimental infection with the Paderborn isolate of classical swine fever virus in 10-week-old pigs: determination of viral replication kinetics by quantitative RT-PCR, virus isolation and antigen ELISA, Vet. Microbiol. (2003) 92:197-212.

[25] Van Oirschot J.T., Description of the virus infection, in: Liess B. (Ed.), Classical swine fever and related viral infections, Martinus Nijhoff Publishing, Dordrecht, 1988, pp. 1-25.

[26] Van Rijn P.A., Wellenberg G.J., Hakze-van der Honing R., Jacobs L., Moonen P.L., Feitsma H., Detection of economically important viruses in boar semen by quantitative RealTime PCR technology, J. Virol. Methods (2004) 120:151-160.

[27] Wallinga J., Lipsitch M., How generation intervals shape the relationship between growth rates and reproductive numbers, Proc. Biol. Sci. (2007) 274:599-604.

[28] Weesendorp E., Stegeman A., Loeffen W., Dynamics of virus excretion via different routes in pigs experimentally infected with classical swine fever virus strains of high, moderate or low virulence, Vet. Microbiol. (2009) 133:9-22.

[29] Wensvoort G., Terpstra C., Boonstra J., Bloemraad M., Van Zaane D., Production of monoclonal antibodies against swine fever virus and their use in laboratory diagnosis, Vet. Microbiol. (1986) 12:101-108. 